\title{
UTILIDAD DEL MÉTODO DE FILTRACIÓN-ADHESIÓN EN CITOLOGÍA URINARIA
}

\author{
Francisco Javier Torres Gómez, A. Torres Gómez y Francisco Javier Torres Olivera.
}

Laboratorio de Citología y Anatomía Patológica. Sevilla. España.

\begin{abstract}
Resumen.- OBJETIVO: Comparar el método de concentración celular por citocentrifugación con el de filtración-adhesión en citología urinaria, valorando principalmente su eficacia diagnóstica y sus inconvenientes.

MÉTODOS: Se han estudiado muestras de orina de micción, procesadas por citocentrifugación y por filtración-adhesión de 100 pacientes para detectar células neoplásicas.

RESULTADOS: El método de filtración-adhesión es superior al de citocentrifugación en la detección de células neoplásicas, no incurriendo en diagnósticos falsos positivos. Los inconvenientes son similares en ambos métodos.

CONCLUSIONES: El método de filtración-adhesión es simple, de bajo coste y más sensible que el de citocentrifugación en la detección de células malignas.
\end{abstract}

Palabras clave: Citología. Orina. Filtros. Citocentrífuga.
Summary.- OBJECTIVES: To compare the cytocentrifugation cellular concentration method for urine cytology with the filtration-adhesion method, mainly evaluating their diagnostic efficacy and their inconveniences.

METHODS: Voiding urine samples from 100 patients were processed by cytocentrifugation and filtration-adhesion to detect neoplastic cells.

RESULTS: The filtration-adhesion method is superior to cytocentrifugation in the detection of neoplastic cells, without false positive results. The inconveniences are similar in both methods.

CONCLUSIONS: The filtration-adhesion method is simple, low-cost, and more sensitive than cytocentrifugation for the detection of malignant cells.

Keywords: Cytology. Urine. Filters. Cytocentrifugation.

\section{INTRODUCCIÓN}

La observación de fragmentos tumorales en la orina de pacientes con cáncer vesical por Sanders en 1864 (1) y las observaciones sobre las células encontradas en la orina por Dickinson (2) en 1869, abren una vía eficaz en el diagnóstico de las neoplasias uroteliales. Desde que en 1892 Ferguson (3) recomendara el examen microscópico del sedimento urinario como el mejor método (excluyendo la cistoscopia) para detectar tumores uroteliales, éste ha mantenido su validez sobre otros marcadores tumorales hasta nuestros días (4). Hasta la aparición de los filtros de membrana y citocentrífugas, la centrifugación ha sido el único método de concentración celular de la orina con resultados no totalmente satisfactorios. Los filtros de membrana, muy útiles para este propósito, requieren cuidadosa manipulación técnica y presentan problemas en cuanto a su procesado, a su observación microscópica y conservación (5). Las citocentrífugas 
simplifican el manejo técnico de las muestras y facilitan la observación microscópica al concentrar el material citológico en un área de observación reducida; sin embargo no resultan rentables a laboratorios con número limitado de muestras urinarias.

Aportamos los resultados obtenidos mediante la técnica de filtración-adhesión (6), un método simple, económico y fiable como alternativa al uso de la citocentrífuga.

\section{MATERIAL Y MÉTODOS}

El ensayo se ha realizado sobre 100 muestras consecutivas de orina de micción reciente correspondientes a 100 pacientes (88 varones y 12 mujeres), procedentes de consultas de urología para el control evolutivo tras resección transuretral de tumores vesicales. De cada paciente se han separado dos muestras de orina: una se ha sometido directamente a citocentrifugación (Cytospin 3, Shandon) y la restante se ha procesado según el método de filtración adhesión (6). Se han utilizado filtros de nitrocelulosa de $25 \mathrm{~mm}$ de diámetro con un poro de 0,45 micras (Millipore, ref. HAWPO2500), expandidos previamente en agua y colocados sobre la rejilla de un sistema de filtración (Millipore XX1002514). Del fondo del recipiente de la orina de micción se obtiene una pequeña cantidad mediante pipeta Pasteur que se deposita sobre el filtro, dejándolo filtrar sin utilizar presión negativa. La velocidad de goteo nos indica el grado de saturación del filtro que cesa cuando es total. La superficie del filtro debe quedar húmeda, sin líquido sobrenadante. Mientras transcurre la filtración se prepara un porta identificado extendiendo sobre una de sus caras una pequeña

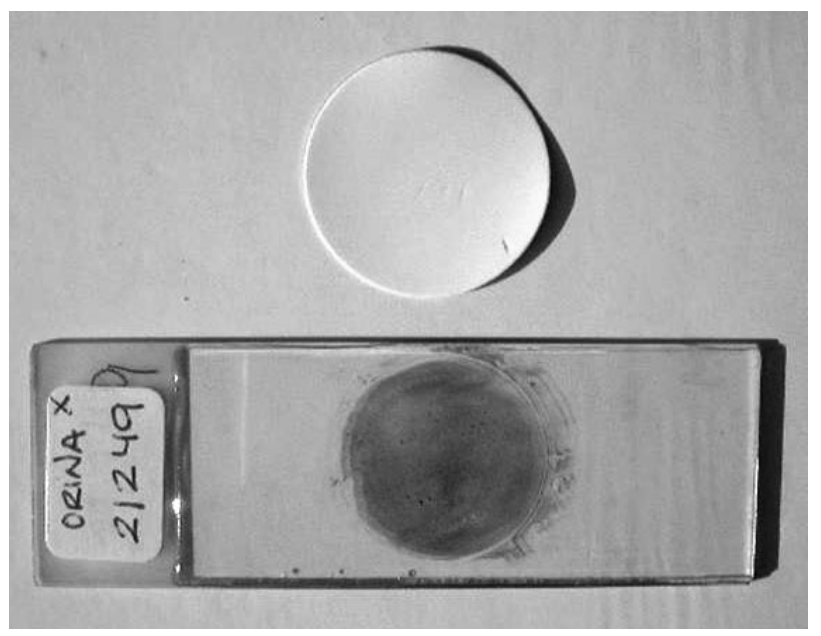

FIGURA 1. Disco extendido sobre portaobjetos. cantidad de gelatina de alumbre de cromo. Sobre esta superficie del porta se impronta la cara celular del filtro, ayudándonos con un papel de filtro de alto grado de absorción con el que se presiona suavemente el filtro sobre el porta. Con una pinza plana se retira cuidadosamente el filtro y el disco celular resultante, claramente definido, se fija con spray comercial. Es importante pulverizar el fijador intermitentemente a una distancia no inferior a $20 \mathrm{~cm}$ a fin de evitar desplazamientos y pérdidas celulares.

Las muestras obtenidas por ambos métodos se tiñen según el método de Papanicolaou, idóneo para la valoración de detalles nucleares.

Los pacientes diagnosticados de carcinoma o sospechosos de carcinoma con cualquiera de los métodos citológicos utilizados fueron sometidos a cistoscopia y biopsia.

El diagnóstico citológico se ha realizado de forma independiente, sin conocer el resultado restante.

\section{RESULTADOS}

20 pacientes mostraron células neoplásicas en las muestras obtenidas mediante fijación-adhesión y 9 en las muestras obtenidas mediante citocentrifugación. En 8 casos ambos métodos detectaron células tumorales y en 1 el diagnóstico correcto se realizó por citocentrifugación. Todos los casos con citología indicativa o sospechosa de carcinoma mostraron en la cistoscopia y biopsia lesión tumoral. 9 casos correspondieron histológicamente a carcinomas uroteliales de bajo grado y 11 a tumores uroteliales de alto grado.

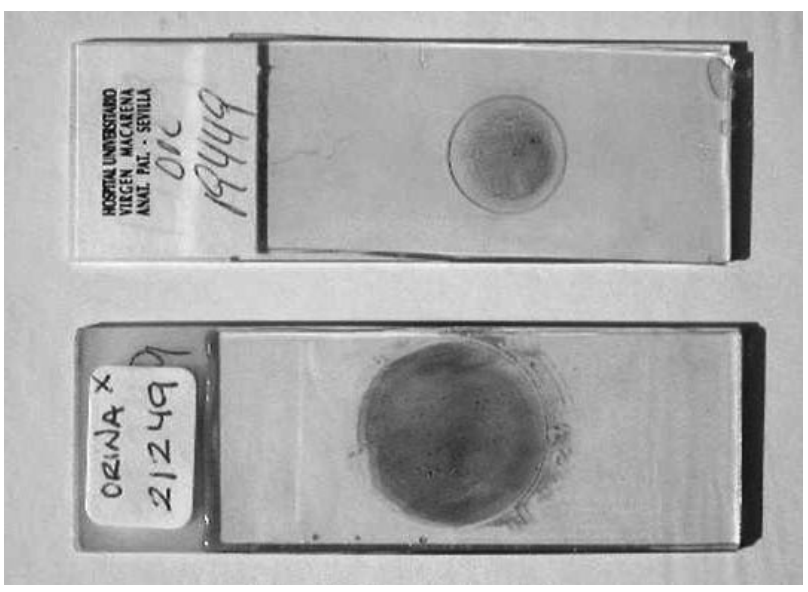

FIGURA 2. Comparación entre el disco extendido sobre el portaobjetos y el disco de la citocentrífuga 


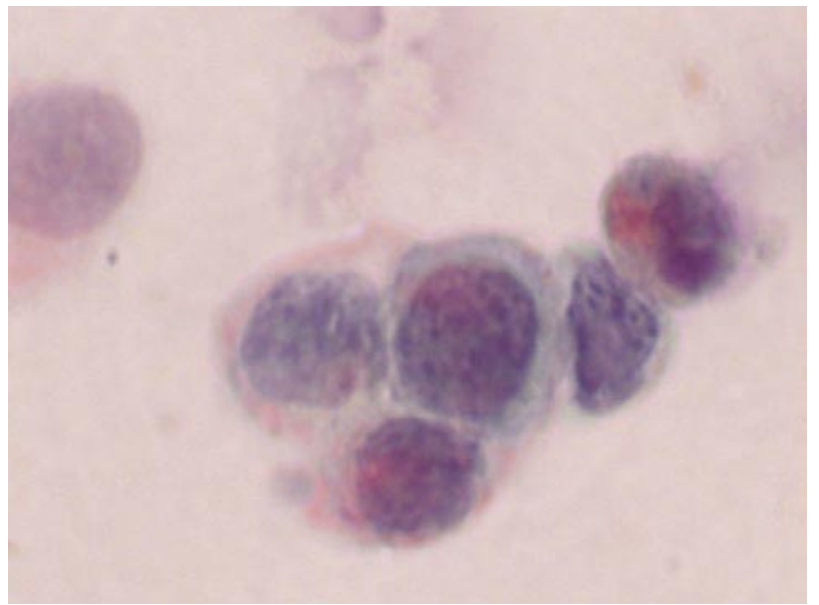

FIGURA 3. Diversos aspectos de discos celulares. Papanicolaou 40x.

Dieciocho muestras no fueron valorables, coincidiendo las causas en ambos métodos en 15 casos: en 7 casos por marcada albuminuria o hematuria, en 4 por cristaluria masiva, en 2 por elevado número de leucocitos y en 2 por exceso de contaminación vulvo-vaginal. De los 3 casos restantes 1 correspondía a carcinoma, diagnosticado correctamente mediante citocentrifugación y que junto a los dos restantes mostraron marcada cristaluria en el método de adhesión-filtración.

\section{DISCUSIÓN}

La citología urinaria mantiene su primacía como test diagnóstico en el despistaje del cáncer urotelial debido a su excelente especificidad, con pocos

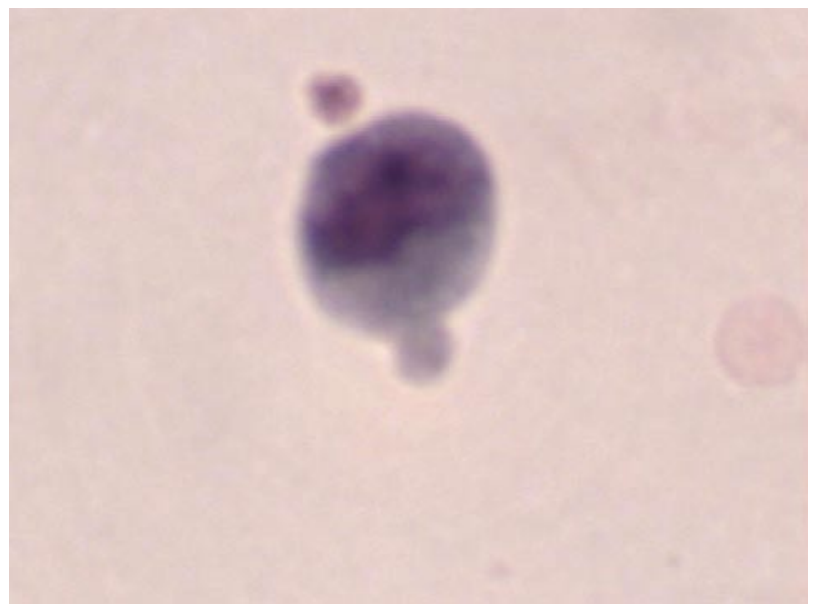

FIGURA 5. Diversos aspectos de discos celulares. Papanicolaou 40x.

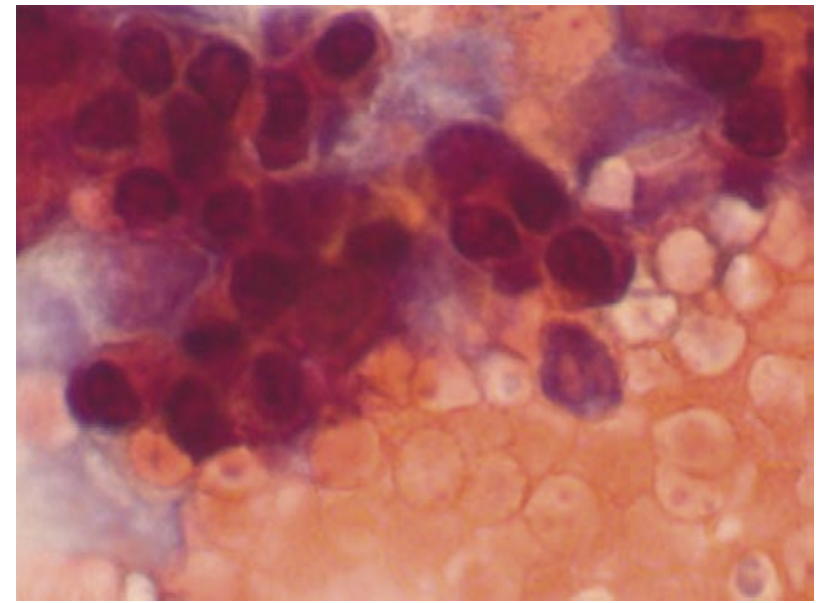

FIGURA 4. Diversos aspectos de discos celulares. Papanicolaou 40x.

falsos positivos $(4,7)$. Aunque su sensibilidad es baja debido a los escasos criterios morfológicos que permiten detectar los tumores de bajo grado, con alta tasa de recurrencia pero escasa capacidad invasora y metastásica, su capacidad diagnóstica de los tumores de alto grado, con agresiva potencialidad evolutiva, es muy alta y muchas veces anticipada a la demostración cistoscópica del tumor, lo que suple con creces este inconveniente $(4,8)$.

La mayor parte de los falsos negativos en citología urinaria se deben, más que a errores interpretativos, a la ausencia de células neoplásicas en el material examinado $(6,9)$. Esta circunstancia puede depender del método de concentración utilizado, de la adhesión celular al portaobjetos o de la fijación. La obtención de sedimento celular mediante centrifuga-

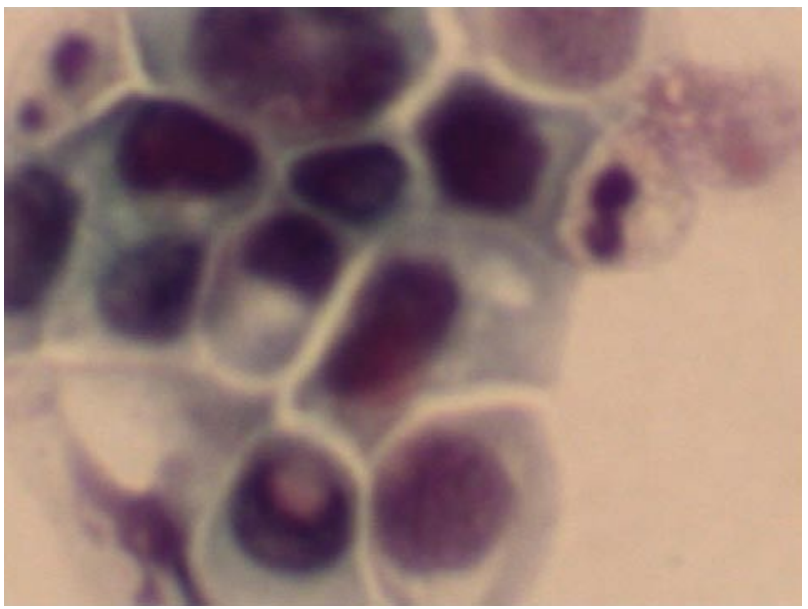

FIGURA 6. Diversos aspectos de discos celulares. Papanicolaou 40x. 
ción, simple o progresivamente enriquecida, ha sido durante mucho tiempo el procedimiento utilizado. Los frotis obtenidos mediante extensión del sedimento muestran un área de observación muy amplia en la que las células aparecen bastante diluidas, lo que alarga el tiempo de observación. La utilización de filtros de membrana tipo Millipore o similares ha mejorado cuantitativa y cualitativamente la muestra urinaria, acortando sustancialmente el tiempo de observación $(10,11,7,9,12,13,14)$, ha permitido realizar morfometría (5), y facilitado la aplicación de técnicas inmunohistoquímicas (15). En nuestra experiencia y la de otros (14), el filtro obtiene mayor celularidad y mejor distribución de la misma en el área de observación que la citocentrífuga, en la que la acumulación celular es frecuente. El filtro como soporte celular es difícil de fijar, teñir, montar y sobre todo conservar (16) por lo que se han utilizado alternativas como la extensión del contenido celular del disco mediante torunda (7), la disolución del disco sobre el porta (17) - la impronta del disco sobre el mismo (6). Hemos aplicado esta última modalidad por su simplicidad técnica, bajo coste y óptimas condiciones de observación.

Las células de la orina tiene escasa adhesividad al portaobjetos, por lo que las pérdidas celulares son importantes en el proceso de fijación (9). La preparación del portaobjetos con gelatina de alumbre de cromo previa a la transferencia celular retiene el $94 \%$ de las células, resultado muy superior al obtenido con otros adhesivos (6). La prefiijación de la orina no aporta ventajas en cuanto a la preservación celular y parece influir negativamente sobre la celularidad de la muestra por lo que es preferible la orina de micción reciente (18). La fijación condiciona

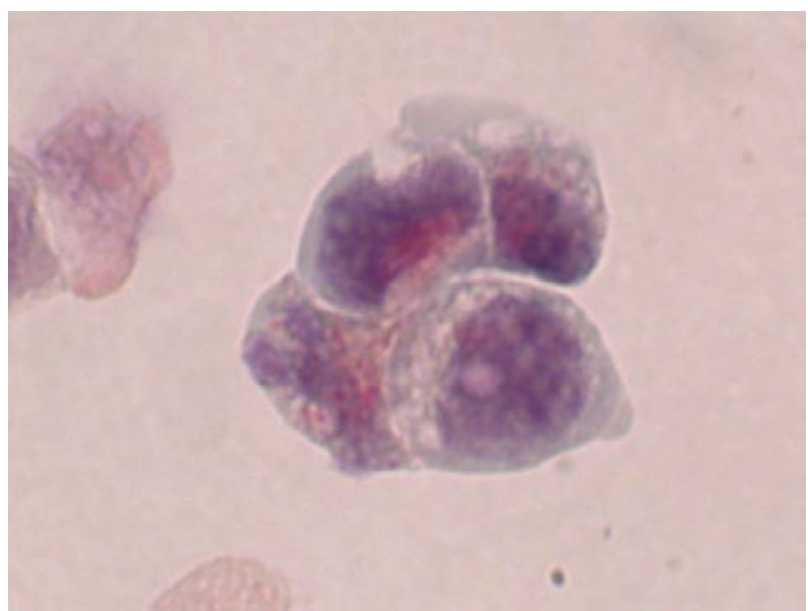

FIGURA 7. Diversos aspectos de discos celulares. Papanicolaou 40x. una pérdida importante de celularidad, independientemente del método de concentración utilizado (9). Las soluciones de formaldehído mantienen adecuado número de células cuando se aplican al método de filtración (19) pero impiden el uso de la tinción de Papanicolaou, utilizada de rutina en la mayor parte de los laboratorios de citología. La fijación con spray comercial, aunque supone una pérdida celular del $40 \%$ es superior a otros tipos de fijación (9).

Los sutiles cambios nucleares presentes en los carcinomas uroteliales de bajo grado obligan a utilizar un método que preserve al máximo la morfología nuclear. La filtración por gravedad evita cualquier efecto mecánico sobre las células. Hemos observado mejor reparto celular en los frotis obtenidos por filtración-adhesión que en los de citocentrífuga y ello probablemente influye sobre la definición celular.

Ambos métodos presentan causas comunes de frotis insatisfactorios. Las cristalurias, albuminurias y hematurias importantes son las causas más habituales. En estos casos el centrifugado previo a la filtración resolvería el problema al poder descartar el fondo del sedimento. Otra causa menos común es la saturación precoz del filtro por un exceso de células escamosas. Nuestros dos casos corresponden a mujeres.

La validez del método de adhesión-filtración queda reflejada en los resultados obtenidos. Todos los casos menos uno con células neoplásicas detectadas mediante citocentrifugación fueron corroborados con este que además diagnostica correctamente once casos más. Con ninguno de los métodos utilizados se obtuvieron falsos positivos. Aunque no hemos podido

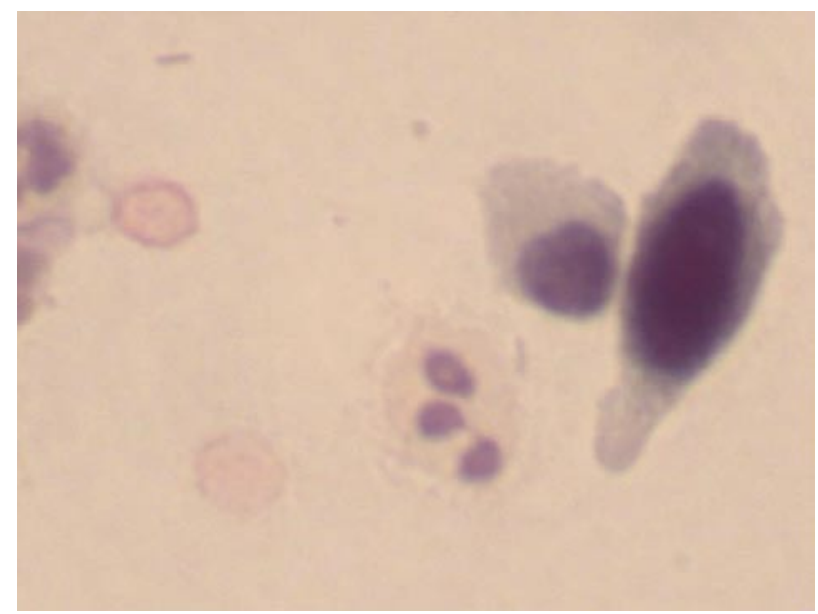

FIGURA 8. Diversos aspectos de discos celulares. Papanicolaou 40x. 
evaluar el número verdadero de falsos negativos con ambos métodos, estos han sido claramente más numerosos en el método de citocentrifugación.

Proponemos este método de estudio de la citología urinaria por su simplicidad, bajo coste, breve consumo de tiempo en el diagnóstico y buenos resultados.

\section{BIBLIOGRAFÍA Y LECTURAS RECOMENDADAS (*lectura de interés $y$ ** lectura fundamental)}

1. SANDERS, W.: "Cancer of the bladder". Edimburg M.J., 111: 273, 1864.

2. DICKINSON, W.: "Portions of cancerous growth passed by the urethra". Tr. Path. Soc. London, 20: $233,1869$.

3. FERGUSON, F.: "The diagnosis of tumors of the bladder by microscopical examination". Proc. NY Path. Soc., pág. 71, 1892.

4. BROWN, F.: "Urine cytology. It is still the gold standard for screening?". Urol. Anal. Quant. Cytol. Histol., 4: 257, 1998.

5. BISHOP, J.; SIMS, K.: "Cellular mophometry in nongynecologic thin-layer and filter cytologic specimens". Clin. North Am., 27: 25, 2000.

*6. NIELSEN, M.; FISCHER, S.; HÖGSBORG, E. y cols.: "Adhesives for retaining prefixed urothelial cells on slides after imprinting from cellulosic filters". Acta Cytol., 27: 371, 1983.

**7. KOÓR, S.; TÖRZSÖI, F.: "Preparation of urine cytologic samples using millipore membrane filters". Z. Urol. Nephrol., 81: 101, 1988.

8. KONETY, B.; METRO, M.; MELHAM, M. y cols.: "Diagnostic value of voided urine and bladder barbotage cytology in detecting transicional cell carcinoma of the urinay tract". Urol. Int., 62: 26, 1999.

*9. BEYER-BOON, M.; VOOR-DEN HOLLANDER, M.: "Cell yield obtained with various cytopreparatory techniques for urinary cytology". Acta Cytol., 22: 589, 1978.

10. HARPST, H.; WARE, R.; EISENBERG, R. y cols.: "Exfoliative cytology of the urinary tract: Evaluation of the millipore technic". Acta Cytol., 5: 195, 1961.

11. FARYNA, J.: "The use of millipore technique in cytodiagnostic studies of urine". Patol. Pol., 41: 129, 1990.

*12. MUSCILLO, M.; CIRRINCIONE, M.; QUINTO, F.: "Use of millipore filters in the cytological study of urine and other fluids". Minerva Ginecol., 27: 470, 1975.

13. TROTT, P.: "Cytological examination of urine using a membrane filter". Br. J. Urol., 39: 610, 1967. 